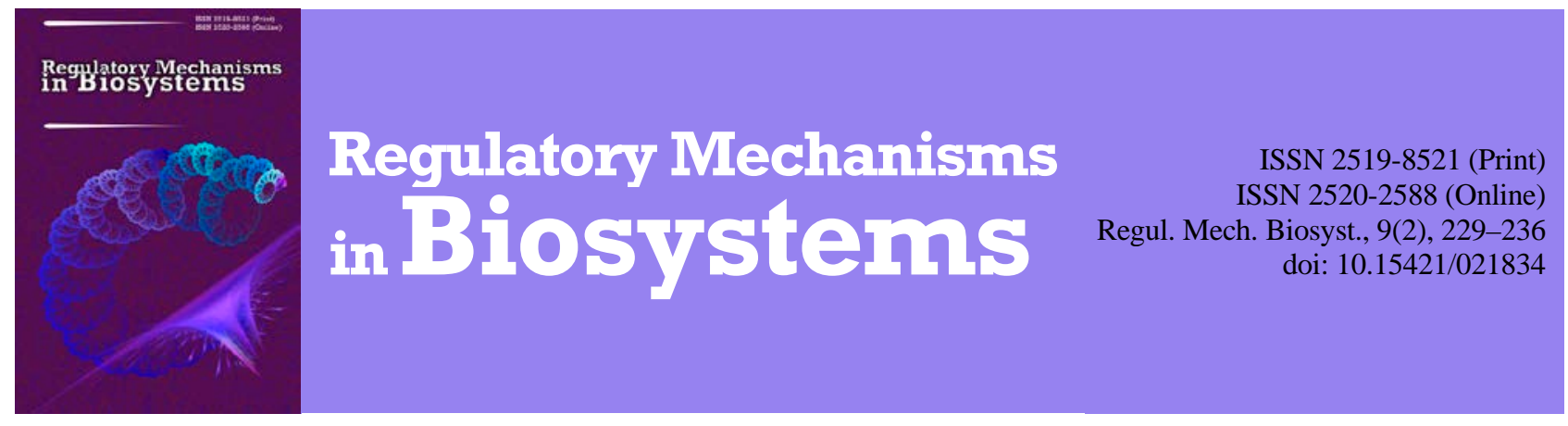

\title{
Comparative morphology and biology of nematodes of genus Heterakis (Nematoda, Heterakidae), parasites of the domestic goose (Anser anser) in Ukraine
}

\author{
V. A. Yevstafyeva*, V. V. Melnychuk *, O. V. Nikiforova**, K. V. Suprunenko*, \\ L. N. Korchan*, T. P. Lokes-Krupka*, I. S. Nehrebetskyi*, N. I. Korchan* \\ *Poltava State Agrarian Academy, Poltava, Ukraine \\ **Kharkiv State Zooveterinary Academy, Kharkiv, Ukraine
}

Article info
Received 16.03.2018
Received in revised form
25.04.2018
Accepted 28.04.2018

Poltava State Agrarian Academy, Skovorody st., 1/3,

Poltava, 36003, Ukraine. Tel.:+38-050-183-78-78. E-mail: evstva@ukr.net

Kharkiv State Zooveterinary Academy, Academichna st., 1 Malaya Danylivka, Dergachi district, Kharkiv, 62341, Ukraine. E-mail: ixodes1795@gmail.com

\begin{abstract}
Yevstafyeva, V. A., Melnychuk, V. V., Nikiforova, O. V., Suprunenko, K. V., Korchan, L. N., Lokes-Krupka, T. P., Nehrebetskyi, I. S., \& Korchan, N. I. (2018). Comparative morphology and biology of nematodes of genus Heterakis (Nematoda, Heterakidae), parasites of the domestic goose (Anser anser) in Ukraine. Regulatory Mechanisms in Biosystems, 9(2), 229236. doi:10.15421/021834
\end{abstract}

The genus Heterakis Dujardin, 1845 is one of the most widely distributed genera of nematode parasites of domestic and wild birds. Geographically and ecologically predominant species include Heterakis gallinarum Schrank, 1788 and Heterakis dispar Schrank, 1790. Prevalence and occurrence of these nematodes in the domestic goose (Anser anser dom.) depend on their biological and morphological specifics which ensure the highest viability, fast growth and maximum fertility in the host. This study presents the abundance and species composition of nematodes of the genus Heterakis in the domestic goose in Ukraine. Comparative study of morphological and metrical characteristics of $H$. gallinarum and H. dispar adult females and males is presented. Additional morphometric characteristics are proposed for easier identification of the two species. Stages and periods of embryonic development of $H$. gallinarum and $H$. dispar nematodes obtained from domestic geese are established according to morphological and metrical characters. Of the two species, H. dispar is prevalent in domestic geese from Poltava, Kharkiv and Kyiv regions. Abundance index of this species is 9.8 specimens, and intensity of infection index is up to 62 specimens. $H$. gallinarum is rarer, its abundance index is 1.2 specimens and maximum intensity of infection is 30 specimens. Species-specific morphological differences are more distinct in male nematodes in the size and structure of the spicules, lateral wing-like protrusions of pseudobursas, numbers and position of tail papillae. Additional metrical characteristics differ between $H$. gallinarum and $H$. dispar nematodes, allowing us to identify not only adult specimens but also eggs. Embryonic development of both species occurs in four morphologically distinct stages: protoplast, blastomere cleavage, formation of first and second stage larvae. Eggs of $H$. gallinarum nematodes become infectious in eight days at $27^{\circ} \mathrm{C}$, eggs of $H$. dispar in four days, their viability in laboratory culture is $84.3 \pm 0.58$ and $91.3 \pm 1.53 \%$ respectively.

Keywords: heterakiasis, Heterakis gallinarum; Heterakis dispar; identification characters; embryogenesis; metrical parameters

\section{Introduction}

Nematodes are one of the leading groups of animals on Earth. Their expected diversity may well equal a million species, and most known species can parasitize in humans, animals and plants (Blaxter et al., 1998; Castagnone-Sereno \& Danchin, 2014). Parasitic nematodes are essential components of biocoenoses; they utilize a lot of energy in ecosystems and can regulate the abundance of their hosts (Bongers \& Ferris, 1999; Lok, 2016; Viney, 2017). Nematodes are the most widely distributed parasites of domestic and wild animals, and the genus Heterakis Dujardin, 1845 includes especially common and prevalent parasite species. Representatives of the genus have been found in domestic chickens in West and South Africa (Phiri et al., 2007; Ogbaje et al., 2012), Great Britain (Pennycott \& Steel, 2001) and Germany (Kaufmann et al., 2011; Wongrak et al., 2014), in Colinus virginianus, Branta bernicla nigricans, Chen caerulescens caerulescens, Chen rossii and Anser albifrons in USA (Moore \& Simberloff, 1990; Shutler et al., 2012; Amundson et al., 2016; Boone et al., 2017), in wild migratory birds and domestic waterfowl in South Asia (Hoque et al., 2014), and in birds of the families Psittacidae, Cacatuidae, Phasianidae and Anatidae in Spain (Cordón et al., 2009). In Ukraine, nematodes of the genus
Heterakis have been found in domestic birds (chickens, turkeys and geese) with prevalence ranging 2.9-100.0\% (Bogach \& Taranenko, 2003; Zaikina \& Marshalkina, 2015).

Heterakis gallinarum Schrank, 1788 is a typical and most common species in domestic and wild terrestrial birds (Gallus gallus dom., Numida meleagris, Meleagris gallopavo, Coturnix coturnix) representtative of the genus (Tompkins et al., 2000; Brener et al., 2006; Sherwin et al., 2013; Al-Moussawi, 2016). In waterfowl (Anser anser dom., Anas platyrhynchos dom.), Heterakis dispar Schrank, 1790 is the most characteristic and common species (Gicik \& Arslan, 2003; Fedynich et al., 2005).

It was however proved that terrestrial birds can be infected with $H$. dispar, and waterfowl with $H$. gallinarum. Hence, these parasites can adapt to uncharacteristic hosts, especially in areas where different bird species are kept or found together (Avcioglu et al., 2008; Hoque et al., 2011; Wang et al., 2012; Kornaś et al., 2015). There are a few reports of these parasitic species being found together in waterfowl (Harradine, 1982; Dube et al., 2010; Nagwa et al., 2013).

Adult $H$. gallinarum and $H$. dispar nematodes are differentiated by morphological specifics of the tail ends in males, namely the shape and length of spicules and the number of tail papillae. Other morphological 
characters are very similar, especially in females which can be considered identical (Abou Znada, 1993; Rahman \& Manap, 2014; Sheikh et al., 2016). There are also diagnostically important metrical species characters, such as length and width of body, size of bulbus and esophagus. In males, other characters include size of preanal sucker, distance from anus to tail end and various parameters describing the position of tail papillae in relation to each other and to other body parts. Metrical characters of females include size of eggs in the vulva and position of the vulva. At the same time, data on metrical characters by different authors for one parasite species from different avian species vary (Avcioglu et al., 2008; Park \& Shin, 2010; Tanveer et al., 2015).

Helminth abundance in general and that of $H$. gallinarum and $H$. dispar in particular in waterfowl populations depends on specifics of parasite biology and their maximum adaptation to the widest variety of hosts. Life cycles of the two parasite species are direct. Embryogenesis of $H$. gallinarum is researched relatively better, while development of H. dispar eggs is a subject of few studies (Clapham, 1933; Roberts, 1937; Madsen, 1950; Skrjabin et al., 1961).

Notably, nematodes of the genus Heterakis as other parasitic organisms are constantly evolving, which is a process associated with morphological, metrical and biological changes. Thus, morphology and biology of Heterakis nematodes should be studied in different species from varying climatic and geographic conditions. Also, new approaches should be implemented in studies of identifying characters in different taxa of the genus. The purpose of this work was to study the fauna, abundance, morphological and biological species-specific characters of nematodes of the genus Heterakis which parasitize domestic geese (Anser anser dom.) in Ukraine.

\section{Materials and methods}

The studies were conducted in 2016-2017 at the Laboratory of Parasitology and Veterinary-Sanitary Expertise of the Department of Veterinary Medicine of Poltava State Agrarian Academy. Material for species identification, abundance and parasitological analysis of nematodes of the genus Heterakis was collected during helminthological investigation of the intestine of 463 domestic geese (Skrjabyn, 1928) from Poltava, Kharkiv and Kyiv regions. Abundance, occurrence and intensity of infection were used to quantify numbers of Heterakis nematodes. The roundworms were identified according to Skrjabyn et al. (1961). In morphological analysis, 568 specimens of the species $H$. gallinarum (173 males and 395 females) and 4,541 specimens of the species $H$. dispar (3,077 males and 1,464 females) were used.

Biological specifics of embryogenesis of $H$. gallinarum and $H$. dispar in culture were studied on eggs collected from the gonads of female nematodes. The eggs were cultured to the infectious stage with the second stage larvae in a Petri dish for 10 days in a thermostat at $27^{\circ} \mathrm{C}$. The cultures were examined daily under a light microscope. Embryonic stage of development and morphological characteristics were studied. Eggs that stopped developing or were destroyed were also noted. Each experiment was performed in triplicate.

To measure metrical characteristics of adult and embryonic nematodes of the genus Heterakis, ImageJ for Windows ${ }^{\circledR}$ (version 2.00) software was used in interactive mode using $5^{\times}, 10^{\times}, 40^{\times}$objective and $10^{\times}$photo eyepiece. To calibrate the image analyzer, the ruled scale of an ocular micrometer was coincided with the scale of stage micrometer included in MikroMed microscope kit. Microphotographs were taken using a digital camera of MikroMed (China) microscope.

Standard deviation (SD) and average values (x) were calculated. Significance of difference between average values in studied groups of nematodes was established using one-way analysis of variance and F-test for $\mathrm{P}<0.05$ confidence level.

\section{Results}

The genus Heterakis in domestic geese from Ukraine is represented by two species, $H$. gallinarum and $H$. dispar. The latter is more common, its prevalence in studied birds was $68.4 \%$. The species $H$. gallinarum was less common, found in $16.4 \%$ of studied birds.
Abundance of both nematode species also varied. Index of Abundance for $H$. dispar was up to 9.8 specimens, intensity of infection was 14.3 specimens in average (ranging from 1 to 62 specimens). The abundance of $H$. gallinarum in geese was much lower, 1.2 specimens with average intensity of infection 7.4 specimens (ranging from 1 to 30 specimens). Helminthological investigation revealled adult male and female nematodes of the genus. Females were almost twice as common as males in both species. Their ratio ranged from $2.1: 1$ (for $H$. dispar) to $2.2: 1$ (for H. gallinarum).

Comparison of morphological characters of $H$. gallinarum and $H$. dispar from domestic geese revealed differentiating characteristics that are more distinct in males. The two species are in general visually identical. The mouth at the head ends of both female and male nematodes of either species is surrounded by three indistinct lips. The esophagus consists of three parts: short pharynx, cylindrical middle part and bulbus. The head end can be slightly curved (Fig. 1).

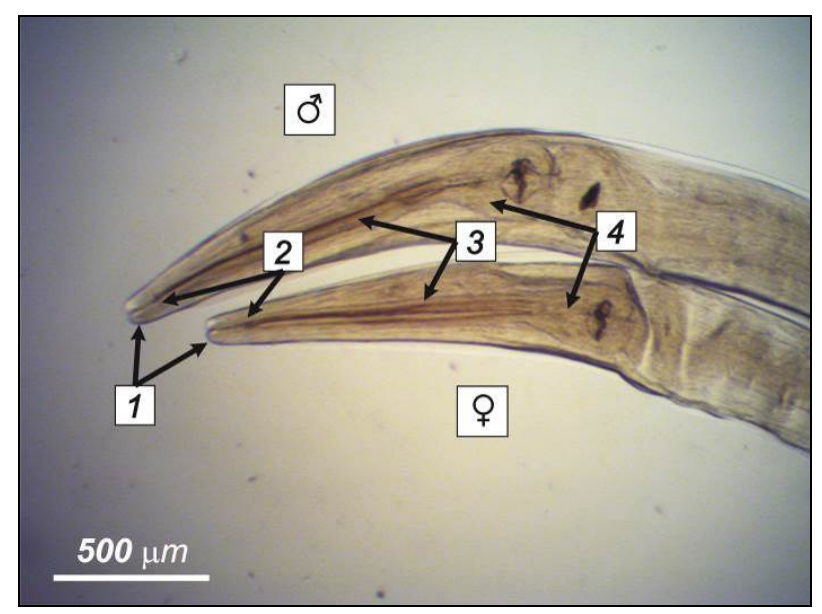

Fig. 1. Head end of nematodes of the genus Heterakis, isolated from geese: 1 -lips, 2 - pharynx, 3 - cylindrical part of esophagus, 4 - bulbus

Females of both species were visually identical. The tail end is elongated, gradually tapered. The anal opening is at the posterior part of body (Fig. $2 d$ ). The vulva of $H$. gallinarum female is located in the middle of the body. There are three bends in the vagina after the vulva, angled posteriorly, anteriorly and once again posteriorly (Fig. 2b). The vulva of the $H$. dispar female is located in the posterior part of body. Another characteristic feature is presence of small wart-like cuticular protrusions in the vulval area. The vagina has bends that are less pronounced than in H. gallinarum females (Fig. $2 a$ ). In both species, the vagina is connected to two opposing uteri. The uteri contain oval eggs with distinct two-contour shells (Fig. 2c).

The main species characters of the studied males were specifics of spicule size and structure, and numbers and position of tail papillae. Male H. gallinarum have stylet-like tail end and pseudobursa with welldeveloped lateral "wings" that smoothly taper. The left spicule is significantly longer than the right, and has a tapered sharp end. The right short spicule is larger, has wing-like protrusions, its distal end is partly coarse, gradually tapered to a pointy hook. Gubernaculum is absent (Fig. 3).

Twelve pairs of tail papillae are located at the tail end (four postanal pairs, six adanal pairs, two preanal pairs) and one medial unpaired precloacal papilla. The preanal sucker is easily seen, round, welldeveloped, surrounded by a chitinized ring (Fig. 4).

The tail pseudobursa of $H$. dispar males also consists of lateral wings. However, they are smaller than in $H$. gallinarum and have wavy edges that follow the shape of the tail papillae, which support the wings. The tail ends into a stylet-like protrusion. Two spicules are visually equal. The proximal ends of both spicules are wide and blunt. Distally, spicules taper to sharp ends. The gubernaculum is absent. Males of $H$. gallinarum similarly to $H$. dispar males have round preanal suckers with a well-developed chitinized ring and an unpaired medial papilla. Distinctively, $H$. dispar males have 13 pairs of tail papillae: four preanal pairs (two pairs of stalked papillae at the sides of the sucker, and two 
lateral pairs of papillae supporting the anterior part of the pseudobursa), four adanal pairs of papillae (two pairs of unstalked papillae at the sides of the anus and two lateral pairs of large papillae that support the middle of the pseudobursa), five postanal pairs of papillae (one pair of large papillae lateral to the anus; one pair of averagely sized papillae directly behind the former; three pairs of small papillae grouped together at the

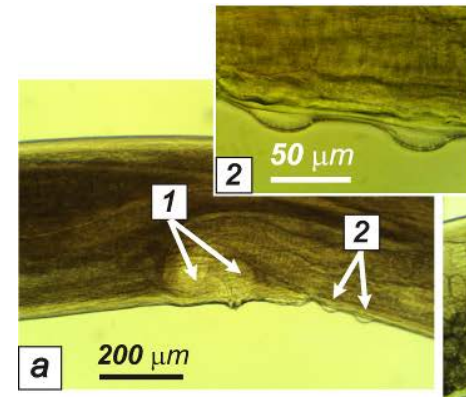

divide between the tail end and tail protrusion) (Fig. 5). Hence, the metrical parameters of adult females and males of $H$. gallinarum and $H$. dispar are significantly different, which is very important in species identification. For males of these species, 20 morphological parameters were found, 19 of which are significantly different and can be considered as taxonomic characters (Table 1). $b-H$. gallinarum vulval area, 3 - vaginal bends; $c$ - eggs in uterus; $d$ - tail end, 4 - anus

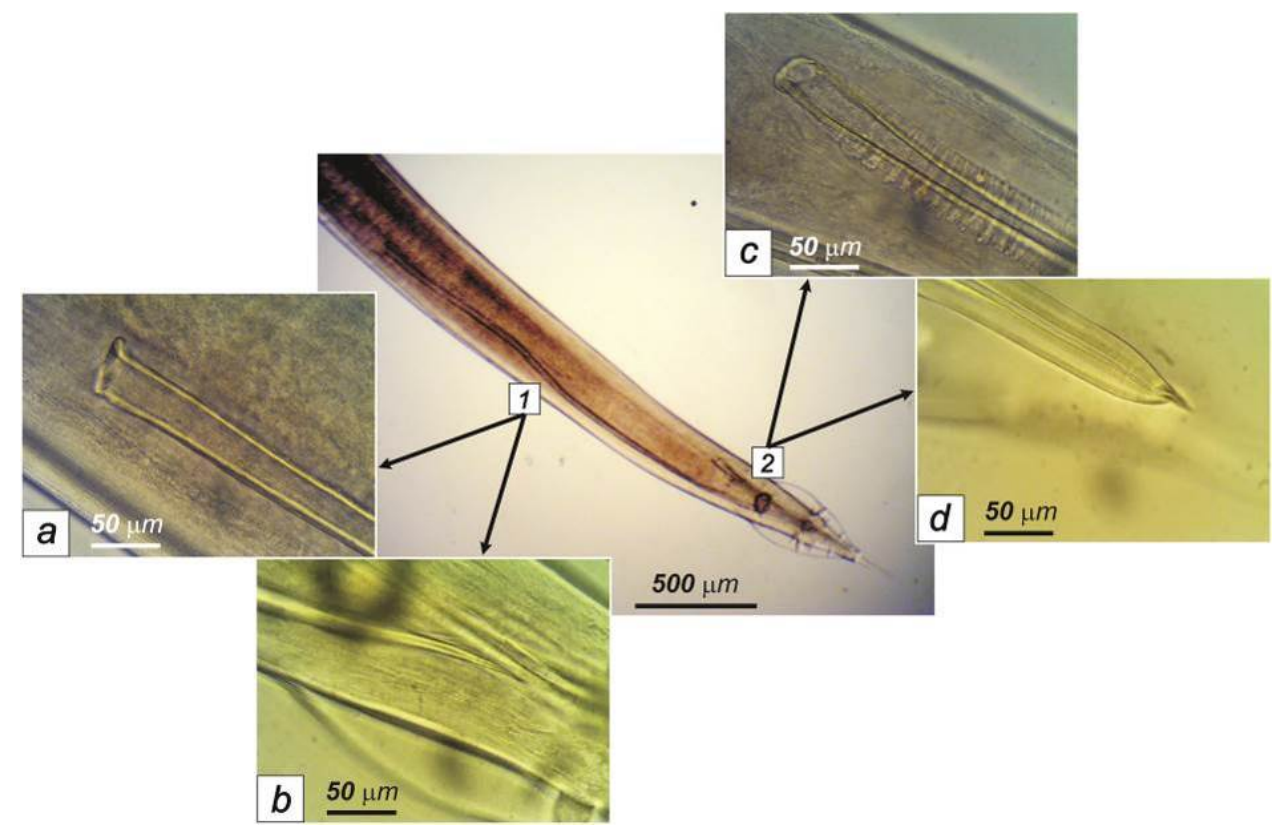

Fig. 3. Spicule structure in $\widehat{\jmath} H$. gallinarum: 1 - left spicule, $a$-proximal end, $b$-distal end; 2 -right spicule, $c$-proximal end, $d$-distal end

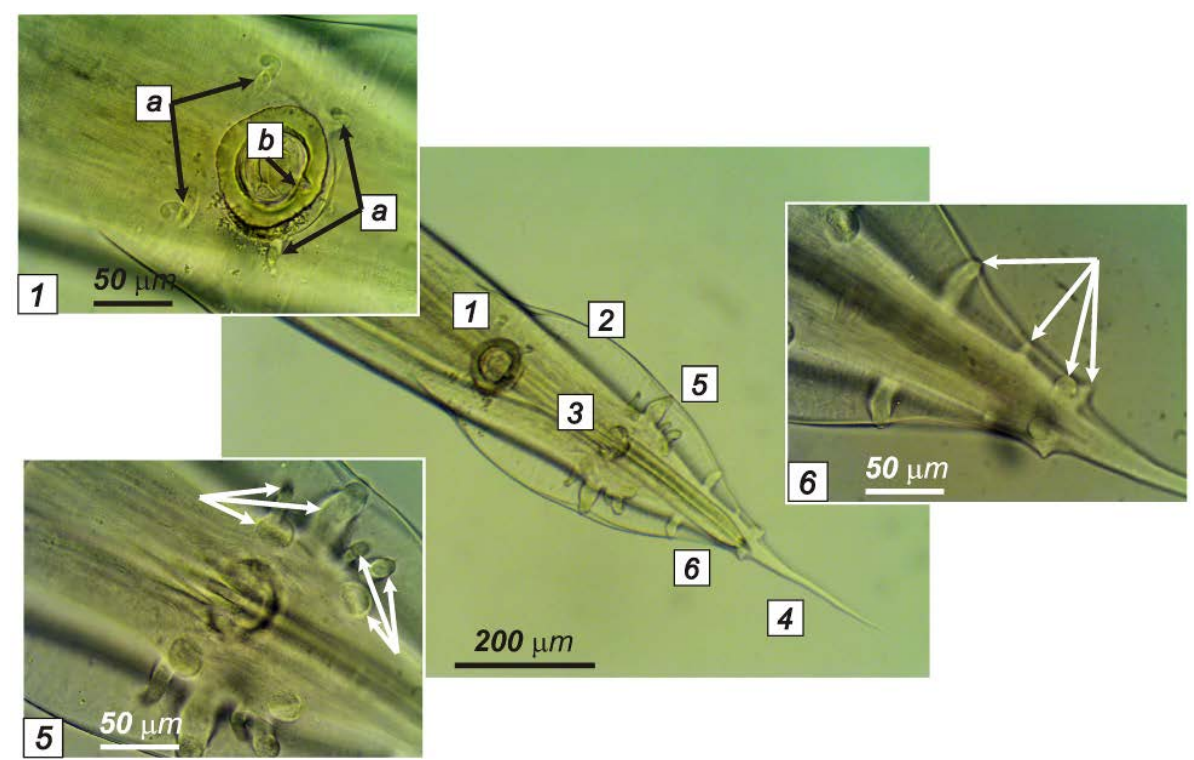

Fig. 4. Tail end of $\hat{\jmath}$ H. gallinarum: 1 - preanal sucker; $a$-position of two preanal pairs of papillae; $b$-medial unpaired papilla; 2 - wings of pseudobursa; 3 - anus; 4 - stylet-like protrusion; 5 - position of six pairs of adanal papillae; 6 - position of four pairs of postanal papillae 

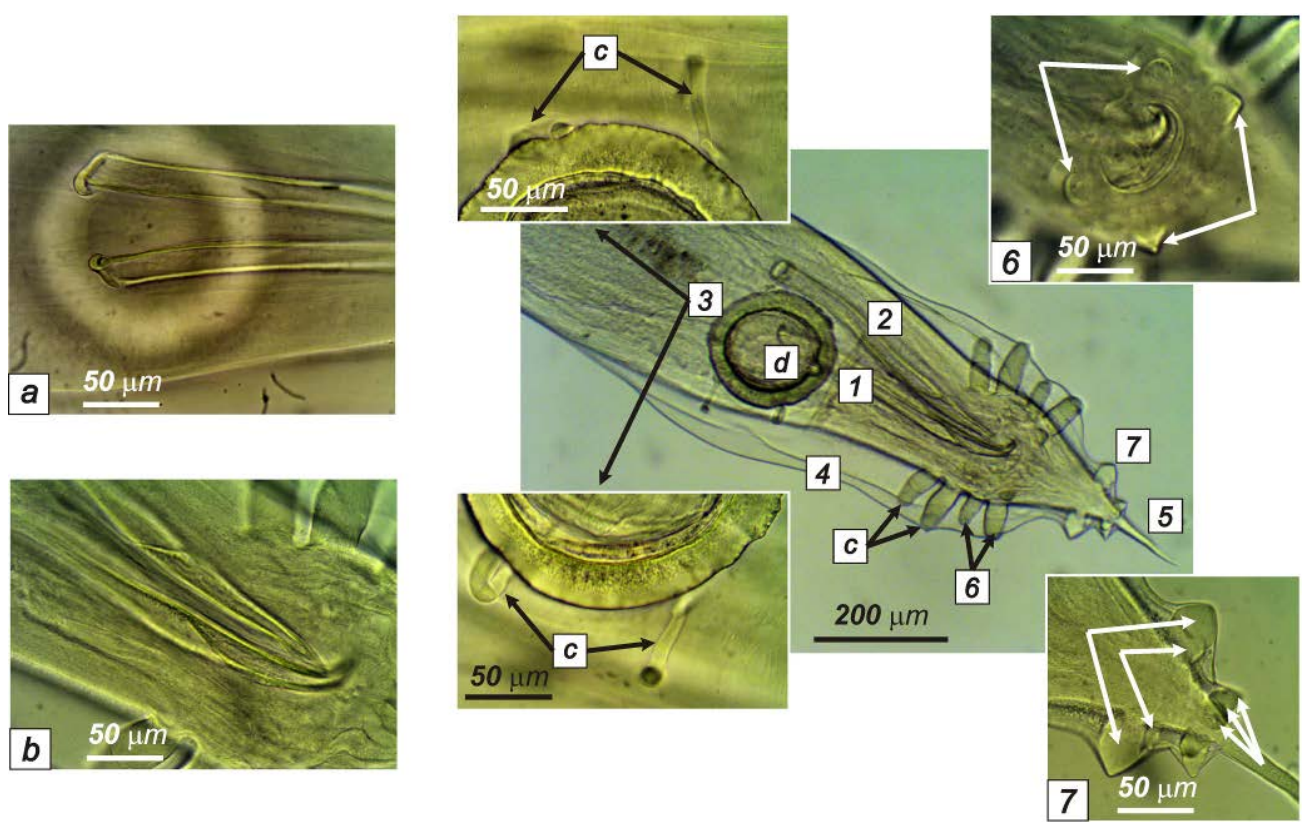

Fig. 5. Tail end $\partial^{\lambda} H$. dispar: 1 - left spicule; 2 - right spicule; $a$-proximal end of spicule, $b$ - distal end of spicule; 3 - preanal sucker, $c$-position of four preanal pairs of papillae, $d$-medial unpaired papilla; 4 - lateral wing of pseudobursa; 5 -stylet-like protrusion;

6 - position of four adanal pairs of papillae; 7 - position of five postanal pairs of papillae

Table 1

Morphometric characters of $\widehat{\partial} H$. dispar and $H$. gallinarum $(\mathrm{n}=20)$

\begin{tabular}{|c|c|c|c|c|c|c|}
\hline \multirow{2}{*}{ Characters } & \multicolumn{3}{|c|}{ H. dispar } & \multicolumn{3}{|c|}{ H. gallinarum } \\
\hline & $\mathrm{x} \pm \mathrm{SD}$ & Min & Max & $\mathrm{x} \pm \mathrm{SD}$ & Min & Max \\
\hline Length of body, mm & $13.36 \pm 0.98$ & 11.58 & 15.67 & $8.26 \pm 1.14^{*}$ & 6.12 & 10.25 \\
\hline \multicolumn{7}{|l|}{ Width of body: } \\
\hline - at bulbus, mm & $0.41 \pm 0.03$ & 0.37 & 0.46 & $0.27 \pm 0.03^{*}$ & 0.23 & 0.32 \\
\hline - in the middle, mm & $0.39 \pm 0.02$ & 0.36 & 0.42 & $0.31 \pm 0.03^{*}$ & 0.27 & 0.38 \\
\hline - at base of wings of pseudobursa, mm & $0.31 \pm 0.02$ & 0.28 & 0.34 & $0.22 \pm 0.02 *$ & 0.19 & 0.25 \\
\hline \multicolumn{7}{|l|}{ Width of pseudobursa wings at: } \\
\hline -preanal sucker, mm & $0.32 \pm 0.02$ & 0.29 & 0.35 & $0.24 \pm 0.01^{*}$ & 0.21 & 0.26 \\
\hline - adanal papillae, $\mathrm{mm}$ & $0.30 \pm 0.02$ & 0.27 & 0.33 & $0.21 \pm 0.01^{*}$ & 0.19 & 0.24 \\
\hline - first pair of postanal papillae, mm & $0.12 \pm 0.01$ & 0.10 & 0.14 & $0.12 \pm 0.02$ & 0.10 & 0.15 \\
\hline - the maximum width of first pair of postanal papillae, mm & $0.34 \pm 0.02$ & 0.31 & 0.38 & $0.28 \pm 0.02 *$ & 0.25 & 0.31 \\
\hline - division between tail end and tail protrusion, $\mathrm{mm}$ & $0.07 \pm 0.01$ & 0.06 & 0.08 & $0.06 \pm 0.01^{*}$ & 0.05 & 0.07 \\
\hline Sucker diameter, $\mu \mathrm{m}$ & $149.58 \pm 5.03$ & 140.88 & 158.69 & $76.00 \pm 3.95^{*}$ & 69.98 & 82.15 \\
\hline Length of medial unpaired papilla, $\mu \mathrm{m}$ & $13.69 \pm 1.69$ & 11.05 & 16.01 & $11.23 \pm 0.80 *$ & 9.67 & 12.19 \\
\hline Width of medial unpaired papilla, $\mu \mathrm{m}$ & $12.01 \pm 1.54$ & 9.42 & 14.39 & $5.64 \pm 0.83^{*}$ & 4.12 & 6.98 \\
\hline Distance from preanal sucker to tail end, mm & $0.57 \pm 0.06$ & 0.44 & 0.67 & $0.63 \pm 0.02 *$ & 0.59 & 0.67 \\
\hline Length of left spicule, mm & $0.39 \pm 0.02$ & 0.37 & 0.42 & $2.27 \pm 0.23^{*}$ & 1.92 & 2.85 \\
\hline \multicolumn{7}{|l|}{ Width of left spicule: } \\
\hline - at proximal end, $\mu \mathrm{m}$ & $29.33 \pm 1.01$ & 27.15 & 30.85 & $43.64 \pm 2.77^{*}$ & 38.14 & 47.22 \\
\hline -in the middle, $\mu \mathrm{m}$ & $25.42 \pm 1.03$ & 23.61 & 27.44 & $21.94 \pm 2.10^{*}$ & 19.54 & 26.33 \\
\hline Length of right spicule, mm & $0.40 \pm 0.01$ & 0.38 & 0.42 & $0.66 \pm 0.07 *$ & 0.55 & 0.77 \\
\hline \multicolumn{7}{|l|}{ Width of right spicule: } \\
\hline - at proximal end, $\mu \mathrm{m}$ & $30.30 \pm 1.34$ & 28.16 & 32.45 & $25.04 \pm 1.76^{*}$ & 22.45 & 28.15 \\
\hline - in the middle, $\mu \mathrm{m}$ & $27.40 \pm 1.29$ & 22.66 & 27.33 & $13.77 \pm 1.27 *$ & 12.00 & 16.33 \\
\hline Left to right spicule length ratio & $0.99: 1$ & $0.88: 1$ & $1.11: 1$ & $3.47: 1^{*}$ & $2.82: 1$ & $4.75: 1$ \\
\hline
\end{tabular}

Note: $*-\mathrm{P}<0.05$ compared to values for $H$. dispar.

According to the metrical data, the values of most parameters (73.6\%) in $H$. gallinarum males are significantly lower than in $H$. dispar. For example, $H$. gallinarum males are shorter (by $38.2 \%, \mathrm{P}<$ 0.05 ) and narrower in different parts of body (by 20.5-34.1\%). The wings of the pseudobursa in $H$. gallinarum males are narrower by 14.2 $30.0 \%(\mathrm{P}<0.05)$ than in $H$. dispar. However, in other areas of the pseudobursa, width parameters are not significantly different for these two species. For example, width of wings of the pseudobursa measured at the level of first postanal papillae is similar in $H$. gallinarum and $H$. dispar ( $0.12 \pm 0.02$ and $0.12 \pm 0.01 \mathrm{~mm}$, relatively). Other characteristic metrical differences in $H$. gallinarum are the two times smaller preanal sucker $(\mathrm{P}<0.05)$ and smaller medial unpaired papilla $(17.9-53.0 \%, \mathrm{P}<$ 0.05 ). In this species, the preanal sucker is located farther from the tail end (by 9.5\%, $\mathrm{P}<0.05$ ) than in H. dispar. Due to morphological differences, males of the two species differ in length of the left spicule, which is confirmed by measurements. In $H$. gallinarum average length of the left spicule was $2.27 \pm 0.23 \mathrm{~mm}$, which is 5.8 times longer $(\mathrm{P}<$ $0.05)$ than in $H$. dispar $(0.39 \pm 0.02 \mathrm{~mm})$. Males of the different species are also significantly different by the following parameters: width of left spicule, size of right spicule. The proximal end of the left spicule in $H$. gallinarum is wider (by $32.7 \%, \mathrm{P}<0.05$ ) and its middle is, conversely, narrower (by $13.6 \%, \mathrm{P}<0.05$ ) compared with $H$. dispar. The right spicules for the two species are visually equal but are statistically different by measurements. The right spicule of male $H$. gallinarum is longer by 39.3\% $(\mathrm{P}<0.05)$ and narrower by $17.3-49.7 \%(\mathrm{P}<0.05)$ than that of $H$. dispar. Respectively the ratios of lengths of right to left spicule are $3.47: 1$ in $H$. gallinarum and $0.99: 1$ in $H$. dispar and are significantly different $(\mathrm{P}<0.05)$. Females of $H$. gallinarum and H. dispar are significantly different by 14 morphological parameters which can make their species identification easier (Table 2). 
Table 2

Morphometric characters of $q H$. dispar and $H$. gallinarum $(\mathrm{n}=20)$

\begin{tabular}{|c|c|c|c|c|c|c|}
\hline \multirow{2}{*}{ Characters } & \multicolumn{3}{|c|}{ H. dispar } & \multicolumn{3}{|c|}{ H. gallinarum } \\
\hline & $\mathrm{x} \pm \mathrm{SD}$ & Min & Max & $\mathrm{x} \pm \mathrm{SD}$ & Min & Max \\
\hline Length of body, mm & $16.43 \pm 1.80$ & 13.18 & 19.25 & $9.41 \pm 0.89 *$ & 7.60 & 11.08 \\
\hline \multicolumn{7}{|l|}{ Width of body: } \\
\hline - at bulbus, mm & $0.51 \pm 0.06$ & 0.39 & 0.62 & $0.34 \pm 0.03^{*}$ & 0.28 & 0.40 \\
\hline - in the middle, mm & $0.58 \pm 0.04$ & 0.52 & 0.65 & $0.37 \pm 0.03^{*}$ & 0.32 & 0.42 \\
\hline - at vulval area, mm & $0.42 \pm 0.02$ & 0.38 & 0.46 & $0.35 \pm 0.03^{*}$ & 0.30 & 0.41 \\
\hline - at anus level, mm & $0.19 \pm 0.01$ & 0.18 & 0.21 & $0.13 \pm 0.02 *$ & 0.10 & 0.16 \\
\hline \multicolumn{7}{|l|}{ Distance: } \\
\hline - from vulva to the last cuticular protrusion, $\mu \mathrm{m}$ & $0.38 \pm 0.04$ & 0.32 & 0.48 & - & - & - \\
\hline - from anus to tail end, $\mathrm{mm}$ & $0.87 \pm 0.04$ & 0.78 & 0.92 & $1.17 \pm 0.05^{*}$ & 1.09 & 1.28 \\
\hline - from head end to vulva, mm & $9.50 \pm 0.92$ & 8.19 & 11.12 & $4.35 \pm 0.37 *$ & 3.19 & 4.98 \\
\hline - from vulva to tail end, mm & $6.93 \pm 0.94$ & 4.94 & 8.25 & $5.06 \pm 0.68 *$ & 3.63 & 6.52 \\
\hline - from vulva to anus, mm & $8.63 \pm 0.92$ & 7.27 & 10.28 & $3.18 \pm 0.37 *$ & 2.07 & 3.86 \\
\hline Egg length, $\mu \mathrm{m}$ & $68.34 \pm 1.52$ & 65.73 & 71.25 & $66.58 \pm 1.57^{*}$ & 63.55 & 69.33 \\
\hline Egg width, $\mu \mathrm{m}$ & $46.24 \pm 1.17$ & 44.25 & 47.98 & $39.01 \pm 0.48 *$ & 38.18 & 39.85 \\
\hline Eggshell width, $\mu \mathrm{m}$ & $1.84 \pm 0.07$ & 1.73 & 1.96 & $1.59 \pm 0.16^{*}$ & 1.22 & 1.82 \\
\hline Area of inner egg surface, $\mu \mathrm{m}^{2}$ & $1798 \pm 57$ & 1713 & 1910 & $1728 \pm 56^{*}$ & 1614 & 1874 \\
\hline
\end{tabular}

Note: $*-\mathrm{P}<0.05$ compared to values for $H$. dispar.

Values of metrical indices of $H$. gallinarum females are lower than those of $H$. dispar, similarly to males. The differences are even more statistically significant in females (100\%) than in males (73.6\%). Females of $H$. gallinarum are shorter (by 1.7 times, $\mathrm{P}<0.05$ ) and consistently narrower (by 1.2-1.6 times, $\mathrm{P}<0.05$ ) compared to $H$. dispar females. Another characteristic difference is the position of the vulva relative to the tail and head ends. In $H$. gallinarum females, the vulva is positioned almost at the middle of the body, and in $H$. dispar females it is positioned nearer to the tail end. The latter species is also characterized by cuticular protrusions near the vulva. Hence we suggest the distance between the vulva and the last cuticular protrusion ( $0.38 \pm$ $0.04 \mu \mathrm{m})$ as a metrical index. The distance between vulva and anus in $H$. gallinarum females was shorter by 2.7 times $(\mathrm{P}<0.05)$ than in $H$. dispar females. Visually, eggs of both nematode species were very alike, however their measurements were statistically different $(\mathrm{P}<0.05)$. All studied egg parameters in $H$. gallinarum nematodes were lower compared to $H$. dispar. Eggs from gonads of $H$. gallinarum females were shorter (by 2.6\%) and narrower (by 15.6\%), their eggshell was thinner (by 13.6\%), and inner egg surface area was lower (by 3.8\%) than in eggs from uteri of $H$. dispar females.

The four stages of embryogenesis of $H$. gallinarum and $H$. dispar at $27^{\circ} \mathrm{C}$ in laboratory culture are protoplast (Fig. 6a), blastomere cleavage
(Fig. 6b), formation of first stage larvae, L1 (Fig. 6c), and second stage larvae, L2 (infectious egg) (Fig. 6d). Infectious eggs developed in $H$. gallinarum in eight days, in $H$. dispar in four days. Viability of $H$. dispar nematode eggs during embryogenesis was $91.3 \pm 1.5 \%$ and was higher than in H. gallinarum ( $84.3 \pm 0.6 \%$ ) (Fig. 7).

All of isolated egg cultures (100\%) were at the protoplast stage. Though the later embryonic development was similar in both species, it varied quantitatively. On the second day culture, $72.7 \pm 2.5 \%$ eggs of $H$. gallinarum were at the blastomere cleavage stage while $55.0 \pm 1.7 \%$ eggs of $H$. dispar contained L1. Also in the second day culture, $23.7 \pm$ $2.1 \%$ of eggs of the latter species contained L2 and were therefore infectious. Development of $H$. gallinarum was longer in comparison: at the fourth day of culture, $55.0 \pm 1.7 \%$ of eggs contained L1. Later, in the sixth to eighth day cultures, numbers of infectious eggs of $\mathrm{H}$. gallinarum increased from $52.7 \pm 1.5$ to $84.3 \pm 0.6 \%$. The development of $15.7 \pm 0.6 \%$ of $H$. gallinarum eggs and $8.7 \pm 1.5 \%$ of $H$. dispar eggs was not successful and they gradually decayed. Morphologically this manifested as broken egg shells, resorption of embryos, air bubbles under egg shells.

Metrical parameters of eggs also changed during embryogenesis. However these changes are very different in $H$. dispar and $H$. gallinarum which can also be used in species identification (Table 3).

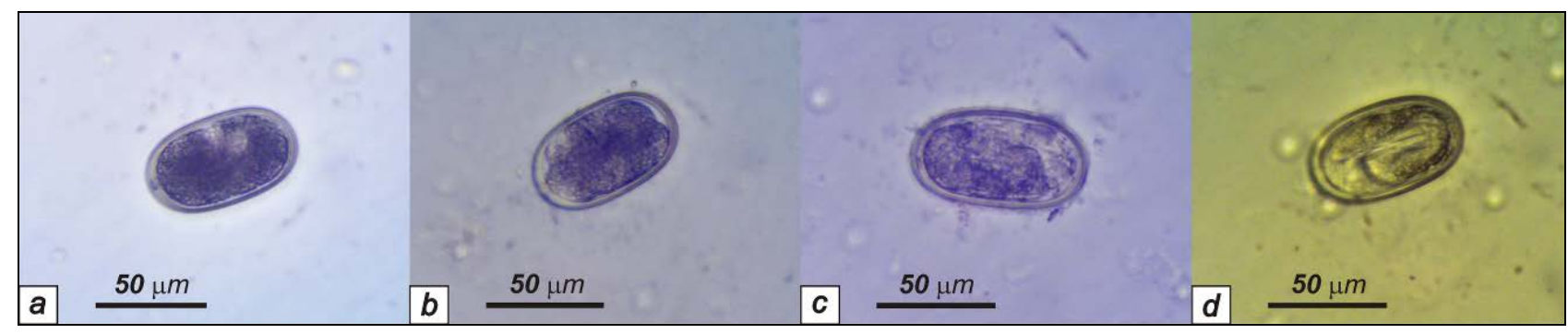

Fig. 6. Embryonic stages of development of Heterakis nematodes from domestic geese: $a$ - protoplast, $b$ - blastomere cleavage, $c-\mathrm{L} 1$ formation, $d-\mathrm{L} 2$ formation (infectious egg)

Table 3

Morphometric parameters of developing Heterakis gallinarum and $H$. dispar eggs in experimental culture $(\mathrm{x} \pm \mathrm{SD}, \mathrm{n}=20)$

\begin{tabular}{lcccc}
\hline \multirow{2}{*}{ Characters } & \multicolumn{2}{c}{ Heterakis dispar } & \multicolumn{2}{c}{ Heterakis gallinarum } \\
\cline { 2 - 5 } & Protoplast stage & L2 stage & Protoplast stage & L2 stage \\
\hline Length, $\mu \mathrm{m}$ & $68.29 \pm 1.46$ & $69.37 \pm 1.84^{*}$ & $66.70 \pm 1.99$ & $64.93 \pm 1.78^{\mathbf{*}}$ \\
Width, $\mu \mathrm{m}$ & $46.10 \pm 1.65$ & $39.02 \pm 1.47^{*}$ & $38.59 \pm 0.87$ & $39.44 \pm 0.92^{*}$ \\
Eggshell thickness, $\mu \mathrm{m}$ & $1.85 \pm 0.09$ & $1.71 \pm 0.10^{*}$ & $1.60 \pm 0.16$ & $1.59 \pm 0.14$ \\
Area of inner egg surface, $\mu \mathrm{m}^{2}$ & $1786 \pm 79$ & $1695 \pm 65^{*}$ & $1711 \pm 67$ & $1739 \pm 75$ \\
\hline
\end{tabular}

Note: $*$ " $-\mathrm{P}<0.05$ compared to values of eggs at protoplast stage. 


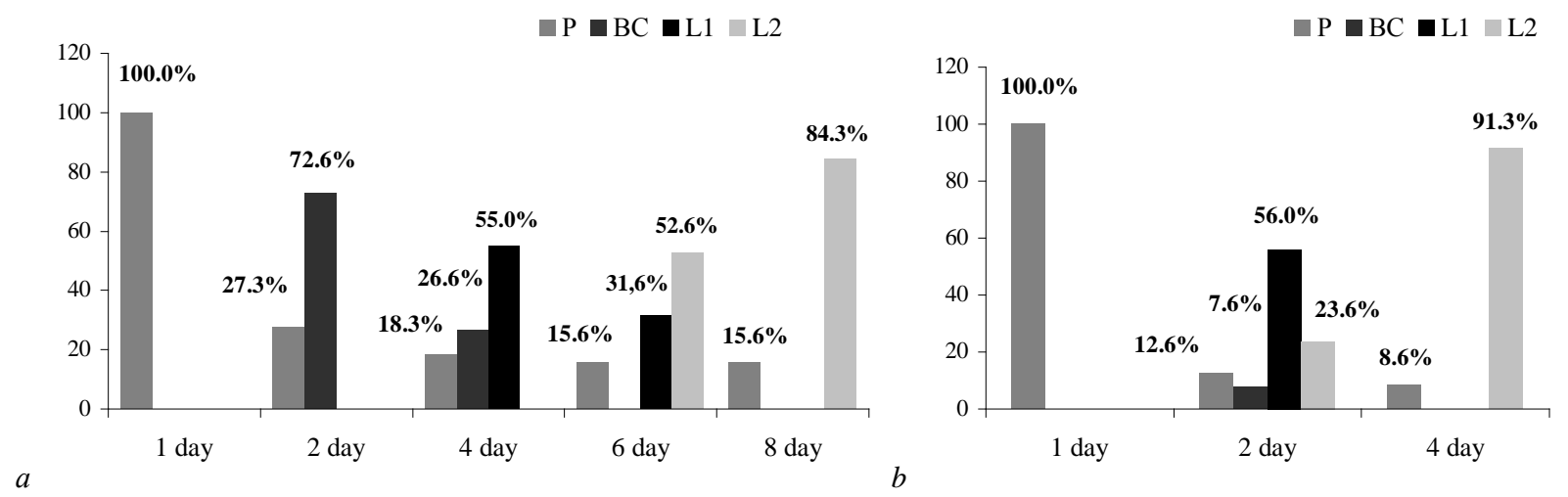

Fig. 7. Embryonic stages of development of Heterakis gallinarum (a) and $H$. dispar (b) in experimental culture in vitro: $P$ - protoplast, $B C$ - blastomere cleavage, L1 - formation of first stage larva, L2 - formation of second stage larva (n = 100)

Eggs of $H$. dispar cultured from protoplast stage to L2 lengthened (by $1.6 \%, \mathrm{P}<0.05$ ), became narrower (by $15.4 \%, \mathrm{P}<0.05$ ), and lost $7.6 \%$ of their eggshell thickness $(\mathrm{P}<0.05)$ and $5.1 \%$ of inner egg surface area $(\mathrm{P}<0.05)$. Length and width of $H$. gallinarum eggs changed during embryonic development, L2 eggs were shorter (by $2.7 \%, \mathrm{P}<0.05$ ) and wider (by $2.2 \%, \mathrm{P}<0.05$ ) compared to protoplast stage, but their eggshell thickness and inner egg surface area did not change. Such changes are connected to different biological species specifics, and possibly to specifics of viability and ability to adapt to nonspecific hosts.

\section{Discussion}

There are two species of the genus Heterakis parasitizing in domestic geese from Poltava, Kharkiv and Kyiv regions of Ukraine. One of them is a specific parasite of geese, $H$. dispar, another, $H$. gallinarum, is mostly adapted to parasitizing in terrestrial birds. The species $\mathrm{H}$. gallinarum was found in domestic geese for the first time in Ukraine. According to many studies, the latter species is widely distributed in domestic, synanthropic and wild terrestrial birds all over the world (Menezes et al., 2001; Malatji et al., 2016; Wuthijaree et al., 2017). In our opinion, $H$. gallinarum adapted to parasitizing geese that were cross-infected when kept together with chickens and turkeys. Density indices also indicate that $H$. dispar nematodes are better adapted to parasitizing domestic geese. The maximum occurrence index of $H$. dispar was $68.4 \%$, maximum abundance was 9.8 , maximum intensity of infection was 62 specimens per host. Density of $H$. gallinarum nematodes in domestic geese was significantly lower and was $16.4 \%$, 1.2 and 7.4 specimens per host, respectively. There are many reports of specificity of $H$. dispar to waterfowl and $H$. gallinarum to terrestrial birds (Skrjabin et al., 1961; Fedynich et al., 2005; Sherwin et al., 2013). However there are several studies showing adaptation of both species to waterfowl and terrestrial birds, especially if hosts are kept or found together (Wang et al., 2012; Nagwa et al., 2013; Kornaś et al., 2015), in accordance to our results.

Comparative analysis of morphological and metrical characteristics of adult male and female $H$. gallinarum and $H$. dispar nematodes resulted in new data on their morphometric structure that can facilitate the species identification. Morphologically, male Heterakis nematodes are more distinct. Males of $H$. dispar have two almost equal spicules and 13 specifically positioned pairs of tail papillae. The lateral wings of their pseudobursas have wavy edges.The left spicules of $H$. gallinarum males are visually longer than the right spicules, there are only 12 pairs of tail papillae, and the lateral wings of the pseudobursa are symmetrically arched. Microscopy study of the structure and position of tail papillae in males of those species shows significant differences. In $H$. dispar there are four preanal, four adanal, and five postanal pairs of papillae. In males of $H$. gallinarum there are two preanal, six adanal, and four postanal pairs of papillae. The position of one unpaired medial papilla is same in both species. These distinct characters in males of both species are confirmed in long-term morphological studies of $H$. gallinarum nematodes obtained mostly from domestic terrestrial birds and $H$. dispar nematodes obtained mostly from waterfowl (Abou Znada, 1993; Rahman \& Manap, 2014; Sheikh et al., 2016). Females are more morphologically similar. We found additional species specific characters of female nematodes, namely cuticular protrusions near the vulva in $H$. dispar, and shape and position of the vaginal bends. In $H$. dispar females, the vaginal bends are shorter and intersecting. In H. gallinarum females they are significantly longer and easily seen in one plane. These morphological characters can be used if male nematodes are absent in a sample, which is a common situation.

Comparison of metrical parameters of adult $H$. gallinarum and $H$. dispar nematodes resulted in 19 parameters in males and 14 in females by which the species statistically differ $(\mathrm{P}<0.05)$. By most measurements $(73.6 \%)$ of male and by all measurements $(100 \%)$ of females $H$. gallinarum nematodes are smaller than $H$. dispar specimens. However, our metrical data on $H$. gallinarum obtained from domestic geese differ from those for specimens obtained from domestic terrestrial poultry. For our specimens, average length of body was $8.26 \pm 1.14 \mathrm{~mm}$ for $H$. gallinarum males, and $9.41 \pm 0.89 \mathrm{~mm}$ for females; width of body ranged from $0.22 \pm 0.02$ to $0.31 \pm 0.03 \mathrm{~mm}$ in males and $0.13 \pm$ 0.02 to $0.37 \pm 0.03 \mathrm{~mm}$ in females. According to other studies, length and width of body can vary from 5.0 to $10.0 \mathrm{~mm}$ and 0.2 to $0.3 \mathrm{~mm}$ in males, and from 6.0 to $13.2 \mathrm{~mm}$ and 0.2 to $0.4 \mathrm{~mm}$ in females of the species (Abou Znada, 1993; Al-Moussawi, 2016; Sheikh et al., 2016). Measurements of Heterakis nematodes obtained from different birds reportedly can vary significantly due to their adaptive variability to more or less suitable hosts (Madsen, 1950). Only a few studies deal with metrical characteristics of $H$. dispar. According to those, the length and width of males range from 10 to $15 \mathrm{~mm}$ and from 0.36 to $0.38 \mathrm{~mm}$, and from 15 to $17 \mathrm{~mm}$ and 0.45 to $0.47 \mathrm{~mm}$ in females, respectively (Madsen, 1950; Skrjabin et al., 1961; Avcioglu et al., 2008). In our study, average length of body was $13.36 \pm 0.98 \mathrm{~mm}$ and width of body $0.31 \pm$ $0.02-0.41 \pm 0.03 \mathrm{~mm}$ in male $H$. dispar specimens, and for females the respective values were $16.43 \pm 1.80 \mathrm{~mm}$ (length of body) and from $0.19 \pm 0.01$ to $0.58 \pm 0.04 \mathrm{~mm}$ (width of body at different areas).

Laboratory cultures revealed that eggs of $H$. gallinarum and $H$. dispar have very similar embryonic development. According to morphological characters, there are four stages of embryonic development: protoplast, blastomere cleavage, formation of L1 and L2 (infectious egg). The egg at the protoplast stage was filled with amorphous mass. At the stage of blastomere cleavage, the protoplast was actively cleaving into round blastomeres. At L1 stage, a mobile though grainy and nebulous larva of indistinct shape was observed. At L2 stage, the larva was mobile, distinctly structured, with graininess in the middle. These data are in line with the published morphological data on egg development of Heterakis, however the stages of embryonic development had not been described before. Comparative study of embryogenesis of $H$. gallinarum and $H$. dispar revealed that eggs from gonads of $H$. dispar females become infectious at $27^{\circ} \mathrm{C}$ in four days with $91.3 \pm$ $1.5 \%$ viability. Eggs from gonads of $H$. gallinarum females developed at the same temperature to infectious stage longer, in eight days with $84.3 \pm 0.6 \%$ viability. Reports on the duration of development of infectious eggs in $H$. gallinarum and $H$. dispar vary significantly. 
According to one study, $H$. gallinarum eggs at $33^{\circ} \mathrm{C}$ become infectious at the fifth day of embryogenesis and at $27{ }^{\circ} \mathrm{C}$ at the seventh day (Roberts, 1937). At 25 to $30^{\circ} \mathrm{C}$, embryogenesis of $H$. gallinarum in the external environmenst is reported to last from 12 to 17 days (Skrjabin et al., 1961). The biology of $H$. dispar is insufficiently studied, there are but a few reports according to which infectious eggs develop in five to six days at $20-24{ }^{\circ} \mathrm{C}$ (Hildenblat, 1956). We also found that metrical parameters of $H$. gallinarum and $H$. dispar eggs during embryogenesis were significantly different. The development of $H$. dispar eggs obtainned from gonads was associated with more changes. They slightly (by $1.6 \%$ ) lengthened, became narrower (by 15.4\%), the eggshell became thinner by $7.6 \%$, inner egg surface area decreased by $5.1 \%$. In our opinion, these changes sustain the high viability of developing eggs. Metrical characteristics of $H$. gallinarum eggs did not change greatly during embryonic development. The eggs became shorter (by 2.7\%) and wider (by 2.2\%). Our data on the duration of development of infectious eggs and their viability can be used in species identification by eggs, if adult helminths are not observed in coprological surveys.

\section{Conclusion}

In Ukraine, there are two species of the genus Heterakis which are adapted to parasitizing domestic goose (Anser anser dom.), $\mathrm{H}$. gallinarum and $H$. dispar. The latter species is more prevalent (occurrence and abundance indices were $68.4 \%$ and 9.8 specimens, respectively). Males of $H$. gallinarum amd $H$. dispar can be differentiated by morphological characters including length and structure of spicules, number and position of tail papillae. Morphological characters used in species identification of females are the shape and position of the bends of the vagina, and in $H$. dispar, presence of cuticular protrusions near the vulva. Nineteen statistically different metrical parameters in males and 14 in females are proposed to assist in differentiation between $H$. gallinarum and $H$. dispar species.

There are four stages in embryonic development of $H$. dispar and H. gallinarum nematodes: protoplast, blastomere cleavage, L1 and L2 formation. The stages are morphologically distinct. Eggs of $H$. dispar become infectious in fourth day culture at $27^{\circ} \mathrm{C}$, and are highly viable (91.3\%). Embryonic development of $H$. gallinarum eggs occurs in eight days, and the average egg viability is $84.3 \%$. The two species differ by changes in egg metrical parameters during embryonic development. In $H$. dispar, significant changes are observed in length and width of eggs, eggshell thickness and inner egg surface area, while in H. gallinarum they are found only in the length and width of eggs. These data add to our understanding of the biological specifics of nematodes of these two species parasitizing in the domestic goose.

\section{References}

Abou Znada, N. Y. (1993). First record and prevalence of the caecal nematodes, Heterakis gallinarum and Subulura suctoria from the Guinea Fowl, Numedia meliagris in Saudi Arabia. Journal of King Saud University, 5(1), 59-65.

Al-Moussawi, A. A. (2016). Nematodes of the Turkey Meleagris gallopavo (Galliformes: Phasianidae) from Al-Nasiryah, Iraq. Journal of Biodiversity and Environmental Sciences, 8(4), 126-131.

Amundson, C. L., Traub, N. J., Smith-Herron, A. J., \& Flint, P. L. (2016). Helminth community structure in two species of arctic-breeding waterfowl parasites and wildlife. International Journal for Parasitology, 5, 263-272.

Avcioglu, H., Burgu, A., \& Bölükbaș, C. S. (2008). Ascaridia numidae (Leiper, 1908; Travassos, 1913) in Rock Partridge (Alectoris chukar) in Turkey. Parasitology Research, 102(3), 527-530.

Blaxter, M. L., De Ley, P., Garey, J. R., Liu, L. X., Scheldeman, P., Vierstraete, A., Vanfleteren, J. R., Mackey, L. Y., Dorris, M., Frisse, L. M., Vida, J. T., \& Thomas, W. K. (1998). A molecular evolutionary framework for the phylum Nematoda. Nature, 392(6671), 71-75.

Bogach, M. V., \& Taranenko, I. L. (2003). Parazytarni hvoroby indykiv fermers'kyh i prysadybnyh gospodarstv Pivdnja Ukrai'ny [Parasitic diseases in turkeys in commercial and household farms of Southern Ukraine]. Ukrainian Black Sea Region Agrarian Science, 21, 311-317 (in Ukrainian).

Bongers, T., \& Ferris, H. (1999). Nematode community structure as a bioindicator in environmental monitoring. Trends in Ecology and Evolution, 14(6), 224-228.
Boone, E. C., Meiners, S. J., \& Laursen, J. R. (2017). Gut helminth composition in newly comigrating light geese (lesser snow goose Chen caerulescens caerulescens and ross' goose Chen rossii). Comparative Parasitology, 84(1), 36-41.

Brener, B., Tortelly, R., Menezes, R. C., Muniz-Pereira, L. C., \& Pinto, R. M. (2006). Prevalence and pathology of the nematode Heterakis gallinarum, the trematode Paratanaisia bragai, and the protozoan Histomonas meleagridis in the turkey, Meleagris gallopavo. Memórias do Instituto Oswaldo Cruz, 101(6), $677-681$.

Castagnone-Sereno, P., \& Danchin, E. G. (2014). Parasitic success without sex the nematode experience. Journal of Evolutionary Biology, 27(7), 1323-1333.

Clapham, P. A. (1933). On the life-history of Heterakis gallinae. Journal of Helminthology, 11(2), 67-86.

Cordón, G. P., Prados, A. H., Romero, D., Moreno, M. S., Pontes, A., Osuna, A., \& Rosales, M. J. (2009). Intestinal and haematic parasitism in the birds of the Almuñecar (Granada, Spain) ornithological garden. Veterinary Parasitology, 165(3-4), 361-366.

Dube, S., Zindi, P., Mbanga, J., \& Dube, C. (2010). A study of scavenging poultry gastrointestinal and ecto-parasites in rural areas of Matebeleland province, Zimbabwe. International Journal of Poultry Science, 9(9), 911-915.

Fedynich, A. M., Finger, R. S., Ballard, B. M., Garvon, J. M., \& Mayfield, M. J. (2005). Helminths of ross' and greater white-fronted geese wintering in South Texas, U.S.A. Comparative Parasitology, 72(1), 33-38.

Gicik, Y., \& Arslan, M. O. (2003). The prevalence of helminths in the alimentary tract of geese (Anser anser domesticus) in Kars District, Turkey. Veterinary Research Communications, 27(5), 391-395.

Harradine, J. (1982). Some mortality patterns of greater magellan geese on the Falkland Islands. Wildfowl, 33, 7-11.

Hildenblat, A. A. (1956). Biologija vozbuditelej ganguleterakidoza gusej Heterakis dispar [Biology of Heterakis dispar, pathogen of ganguleterakidosis in geese]. Collection of Scientific Works of Moscow Veterinary Academy, 12, 207-213 (in Russian).

Hoque, M. A., Hassan, M. M., Haque, E., Shaikat, A. H., Khan, S. A., Alim, A., Skerratt, L. F., Islam, A., Tun, H. M., Dissanayake, R., Day, T. K., Debnath, N. C., \& Yamage, M. (2014). A survey of gastro-intestinal parasitic infection in domestic and wild birds in Chittagong and Greater Sylhet, Bangladesh. Preventive Veterinary Medicine, 117(1), 305-312.

Hoque, M. A., Skerratt, L. F., Rahman, M. A., Alim, M. A., Grace, D., Gummow, B., Rabiul Alam Beg, A. B., \& Debnath, N. C. (2011). Monitoring the health and production of household jinding ducks on Hatia Island of Bangladesh. Tropical Animal Health and Production, 43(2), 431-440.

Kaufmann, F., Daş, G., Sohnrey, B., \& Gauly, M. (2011). Helminth infections in laying hens kept in organic free range systems in Germany. Livestock Science, 141(2-3), 182-187.

Kornaś, S., Basiaga, M., Kowal, J., Nosal, P., Wierzbowska, I., \& Kapkowska, E. (2015). Zatorska goose - a subject of parasitological research. Annals of Parasitology, 61(4), 253-256.

Lok, J. B. (2016). Signaling in parasitic nematodes: Physicochemical communication between host and parasite and endogenous molecular transduction pathways governing worm development and survival. Current Clinical Microbiology, 3(4), 186-197.

Madsen, H. (1950). Studies on species of Heterakis (nematodes) in birds. Danish Review of Game Biology, 1(3), 1-43.

Malatji, D. P., Tsotetsi, A. M., van Marle-Koster, E., \& Muchadeyi, F. C. (2016). A description of village chicken production systems and prevalence of gastrointestinal parasites: Case studies in Limpopo and KwaZulu-Natal provinces of South Africa. Onderstepoort Journal of Veterinary Research, 83(1), a968.

Menezes, R. C., Mattos, J. D. G., \& Tortelly, R. (2001). Freqüência e patologia das infecções causadas por nematóides e cestóides em galinhas-d’angola (Numida meleagris Linnaeus, 1758) criadas extensivamente no estado do Rio de Janeiro, Brasil. Revista Brasileira de Ciência Veterinária, 8, 35-39.

Moore, J., \& Simberloff, D. (1990). Gastrointestinal helminth communities of Bobwhite Quail. Ecology, 71(1), 344-359.

Nagwą E. A., Loubną M. A., El-Madawy R. S., \& Toulą̧E. I. (2013). Studies on helminthes of poultry in Gharbia governorate Benha. Veterinary Medical Journal, 25(2), 139-144.

Ogbaje, C. I., Agbo, E. O., \& Ajanusi, O. J. (2012). Prevalence of Ascaridia galli, Heterakis gallinarum and tapeworm infections in birds slaughtered in makurdi township. International Journal of Poultry Science, 11(2), 103-107.

Park, S. I., \& Shin, S. S. (2010). Concurrent Capillaria and Heterakis infections in zoo rock partridges, Alectoris graeca. Korean Journal of Parasitology, 48(3), 253-257.

Pennycott, T. W., \& Steel, F. (2001). Parasitic worms in commercial free-range poultry flocks in England and Wales. Veterinary Record, 149(14), 428.

Phiri, I. K., Phiri, A. M., Ziela, M., Chota, A., Masuku, M., \& Monrad, J. (2007). Prevalence and distribution of gastrointestinal helminths and their effects on weight gain in free-range chickens in Central Zambia. Tropical Animal Health and Production, 39(4), 309-315. 
Rahman, W. A., \& Manap, N. H. (2014). Descriptions on the morphology of some nematodes of the Malaysian domestic chicken (Gallus domesticus) using scanning electron microscopy. Malaysian Journal of Veterinary Research, 5(1), 35-42.

Roberts, F. H. S. (1937). Studies on the life history and economic importance of Heterakis gallinae (Gmelin, 1790 Freeborn, 1923), the caecum worm of fowls. Australian Journal of Experimental Biology and Medical Science, 15(4), 429-439.

Sheikh, B. A., Ahmad, F., \& Sof, T. A. (2016). Morphology and prevalence of some helminth parasites in Gallus domesticus from Gurez Valley of Jammu and Kashmir, India. Journal of Fisheries and Livestock Production, 4(1), 159.

Sherwin, C. M., Nasr, M. A., Gale, E., Petek, M., Stafford, K., Turp, M., \& Coles, G. C. (2013). Prevalence of nematode infection and faecal egg counts in freerange laying hens: Relations to housing and husbandry. British Poultry Science, 54(1), 12-23.

Shutler, D., Alisauskas, R. T., \& McLaughlin, J. D. (2012). Associations between body composition and helminths of lesser snow geese during winter and spring migration. International Journal for Parasitology, 42(8), 755-760.

Skrjabin, K. I. (1928). Metod polnyh gel'mintologicheskih vskrytij pozvonochnyh, vkljuchaja cheloveka [The method of complete helminthological autopsy of vertebrates, including humans]. Moscow State University, Moscow (in Russian).

Skrjabin, K. I., Shikhobalova, N. P., Lagodovskaya, E. A. (1961). Osnovy nematodologii: Oksiuratozy zhivotnyh i cheloveka [Essentials of nematodology. Oxyurata of animals and man]. Russian Academy of Sciences, Moscow (in Russian).

Tanveer, S., Ahad, S., \& Chishti, M. Z. (2015). Morphological characterization of nematodes of the genera Capillaria, Acuaria, Amidostomum, Streptocara,
Heterakis, and Ascaridia isolated from intestine and gizzard of domestic birds from different regions of the temperate Kashmir valley. Journal of Parasitic Diseases, 39(4), 745-760.

Tompkins, D. M., Greenman, J. V., Robertson, P. A., \& Hudson, P. J. (2000). The role of shared parasites in the exclusion of wildlife hosts: Heterakis gallinarum in the ring-necked pheasant and the grey partridge. Journal of Animal Ecology, 69(5), 829-840.

Viney, M. (2017). How can we understand the genomic basis of nematode parasitism? Trends in Parasitology, 33(6), 444-452.

Wang, X. Q., Lin, R. Q., Gao, Y., Cheng, T., Zou, S. S., He, Y., Li, G. Y., Weng, Y. B., \& Zhu, X. Q. (2012). Prevalence of intestinal helminths in domestic goose (Anser domesticus) in Qingyuan, Guangdong Province, China. African Journal of Microbiology Research, 6(40), 6843-6846.

Wongrak, K., Daş, G., Moors, E., Sohnrey, B., \& Gauly, M. (2014). Establishment of gastro-intestinal helminth infections in free-range chickens: A longitudinal on farm study. Berliner und Münchener tierärztliche Wochenschrift, 127, 314-321.

Wuthijaree, K., Lambertz, C., \& Gauly, M. (2017). Prevalence of gastrointestinal helminth infections in free-range laying hens under mountain farming production conditions. British Poultry Science, 58(6), 649-655.

Zaikina, G. V., \& Marshalkina, T. V. (2015). Epizootychna sytuacija shhodo shlunkovo-kyshkovyh invazij sil's'kogospodars'koi' ptyci central'nogo regionnu Ukrainy [Epizootic situation of gastrointestinal invasions of poultry of the central region of Ukraine]. Journal of Veterinary Medicine of Ukraine, 5, 13-15 (in Ukrainian). 